\title{
High-risk cardiac surgery as an alternative to transplant or mechanical support in patients with end-stage heart failure
}

\author{
Hiroyuki Kawajiri, MD, Cedric Manlhiot, PhD, Heather Ross, MD, Diego Delgado, MD,
} Filio Billia, MD, PhD, Michael McDonald, MD, and Vivek Rao, MD, PhD

\section{ABSTRACT}

Objective: Although the results of cardiac surgery in patients with poor left ventricular function have been widely published, the outcomes in patients with endstage heart failure who meet criteria for advanced therapies are not well investigated. As access to transplantation and ventricular assist device therapy remains limited, we explored the possibility of conventional surgery as an alternative option for highly selected patients with end-stage heart failure.

Methods: We identified patients with left ventricular ejection fraction $<20 \%$ and $\mathrm{VO}_{2} \max <14 \mathrm{~mL} / \mathrm{min} / \mathrm{m}^{2}$, who were initially referred for advanced therapies but were instead offered a conventional procedure from 2002 to 2012 . We examined the short- and midterm outcomes and compared survival with that after our advanced therapies in the same era.

Results: A total of 133 patients were identified; 68 were deemed to be transplanteligible, whereas 65 were transplant-ineligible. Seventy-nine percent were in New York Heart Association class III/IV. In-hospital mortality was 12\%. Actuarial survival at 5 and 10 years was $72 \% \pm 4 \%$ and $39 \% \pm 8 \%$, respectively. Nonischemic etiology was identified as a predictor of late mortality. In the propensity-adjusted model, our transplant-eligible patients had comparable long-term survival to our transplantation patients (HR 1.48 [95\% confidence interval, 0.66-3.2], $P=.34$ ), whereas the survival in our transplant-ineligible subset was comparable to the survival after our left ventricular assist device therapy (HR 0.49 [95\% confidence interval, 0.16-1.50], $P=.21$ ).

Conclusions: Despite high perioperative risk, the midterm survival after conventional surgery in patients eligible for advanced therapies seems to be acceptable and may be an alternative option for highly selected patients with end-stage heart failure. (J Thorac Cardiovasc Surg 2017;154:517-25)

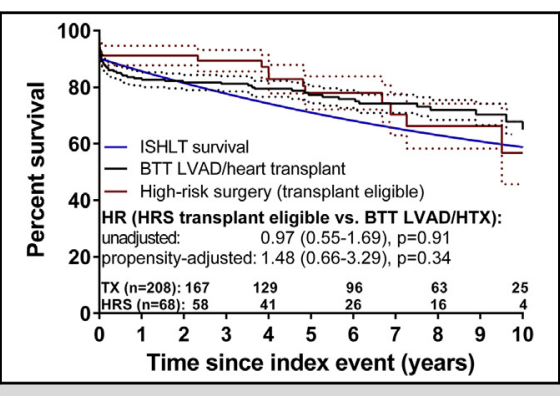

Long-term survival after conventional surgeries for end-stage heart failure patients.

\section{Central Message}

High-risk conventional cardiac surgery provides acceptable midterm survival for highly selected patients with end-stage heart failure.

\section{Perspective}

There is a spectrum of patients with poor left ventricular ejection fraction who present for surgical consideration, a subset of whom are initially referred for transplantation or ventricular assist device. We found that conventional cardiac surgery in this subgroup of patients provided acceptable midterm survival and may be a suitable option for highly selected patients with end-stage heart failure.

See Editorial Commentary page 526.

See Editorial page 515.
Although many preventive and pharmacological approaches have been introduced, more than 650,000 new patients with heart failure (HF) are diagnosed annually in the

\footnotetext{
From the Divisions of Cardiovascular Surgery and Cardiology, Ted Rogers Centre for Heart Research, Peter Munk Cardiac Centre, University Health Network, Toronto, Ontario, Canada.

Received for publication Oct 5, 2015; revisions received Jan 31, 2017; accepted for publication March 4, 2017; available ahead of print May 8, 2017

Address for reprints: Vivek Rao, MD, PhD, Toronto General Hospital, 4PMB-457, 200 Elizabeth St, Toronto, Ontario M5G 2C4, Canada (E-mail: Vivek.Rao@uhn. ca).

$0022-5223 / \$ 36.00$

Copyright (c) 2017 by The American Association for Thoracic Surgery

http://dx.doi.org/10.1016/j.jtcvs.2017.03.040
}

United States and the prevalence is still rising. ${ }^{1}$ The most definitive treatment for refractory end-stage HF has been heart transplantation (HTx); however, donor scarcity still remains a critical issue and waiting times to transplantation continue to increase. ${ }^{2}$ Left ventricular assist devices (LVAD) were initially introduced as a bridge to transplantation, but more recently most LVAD recipients represent

Scanning this QR code will take you to the article title page.

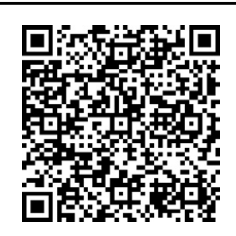




\begin{tabular}{|c|c|}
\hline \multicolumn{2}{|c|}{ Abbreviations and Acronyms } \\
\hline AV & $=$ aortic valve \\
\hline BTT & $=$ bridge-to-transplant \\
\hline CABG & $=$ coronary artery bypass grafting \\
\hline $\mathrm{CI}$ & $=$ confidence interval \\
\hline DCM & $=$ dilated cardiomyopathy \\
\hline DT & $=$ destination therapy \\
\hline $\mathrm{HF}$ & $=$ heart failure \\
\hline HR & $=$ hazard ratios \\
\hline HRS & $=$ high-risk conventional surgery \\
\hline HTx & $=$ heart transplantation \\
\hline IABP & $=$ Intra-aortic balloon pump \\
\hline INTERM & $=$ Interagency Registry for \\
\hline & $\begin{array}{l}\text { Mechanically Assisted Circulatory } \\
\text { Support }\end{array}$ \\
\hline ISHLT & $\begin{aligned}= & \text { International Society for Heart and } \\
& \text { Lung Transplantation }\end{aligned}$ \\
\hline LVAD & $=$ left ventricular assist devices \\
\hline LVDd & $\begin{aligned}= & \text { left ventricular end-diastolic } \\
& \text { diameter }\end{aligned}$ \\
\hline LVEF & $=$ left ventricular ejection fraction \\
\hline MV & $=$ mitral valve \\
\hline NYHA & $=$ New York Heart Association \\
\hline $\mathrm{VO}_{2} \max$ & $=$ maximal oxygen consumption \\
\hline
\end{tabular}

"destination therapy (DT)" and are HTx ineligible. ${ }^{3,4}$ Although DT-LVAD is now widely accepted as an alternative advanced surgical option for patients with end-stage HF, they remain associated with a high adverse event rate and few patients survive event-free beyond 5 years. ${ }^{5}$

Because of the marked limitations in both of these advanced surgical therapies, surgeons are often forced to make a difficult decision when they encounter patients with end-stage HF who have cardiac lesions amenable to conventional surgery. Although the immediate perioperative risk is widely recognized, the long-term benefit of conventional surgeries for this extreme subset is less well characterized. ${ }^{6}$ In addition, most of the studies investigating the outcomes of "high-risk" cardiac surgeries used only left ventricular ejection fraction (LVEF) as an inclusion criteria, ${ }^{7-15}$ but LVEF alone may not be adequate to identify end-stage HF. ${ }^{1,16}$ Therefore, we investigated the outcomes of conventional cardiac surgery in patients who met the criteria for advanced surgical therapies to explore its possibility as an alternative option for end-stage HF.

\section{METHODS}

\section{Patient Enrollment}

We reviewed our institutional database to find all surgical patients who had a preoperative $\mathrm{LVEF}<20 \%(\mathrm{n}=648)$ from May 2002 to Apr 2012. Among them, we identified 377 patients who were initially referred to our HF team for advanced surgical therapies, including HTx or any strategy of LVAD therapy.
Although the 271 excluded patients who were directly referred for conventional cardiac surgeries were not specifically reviewed, these likely represented patients with acute-onset disease in whom myocardial function was expected to recover after surgical intervention (ie, stunned myocardium after acute myocardial infarction or high-gradient aortic stenosis). Alternatively, these patients may have not met inclusion criteria for transplantation (maximal oxygen consumption $\left[\mathrm{VO}_{2} \max \right]>14$ ). The remaining 377 patients underwent 434 procedures, which were classified according to primary therapy and intention-to-treat. A first group of 133 patients underwent high-risk conventional surgery (HRS) of whom 68 were transplant candidates and 65 were not. Those operations included coronary artery bypass grafting (CABG), valve intervention, and LV reconstruction; 2 of these patients eventually underwent HTx. The second group included 208 patients who were eligible for transplant and underwent HTx or bridge-to-transplant (BTT-) LVAD as their primary therapy (155 HTx and 53 BTT-VAD). Twenty-eight patients with BTT-VAD eventually underwent HTx during their follow-up. The third and final group included 36 patients who were not eligible for transplantation and underwent LVAD implantation as DT (Figure 1).

\section{Eligibility for Advanced Surgical Therapies}

All 377 (133 HRS, 208 HTx/BTT-VAD, 36 non-BTT-VAD) enrolled patients were initially referred for advanced surgical therapies and their eligibility for these therapies was preoperatively evaluated by our multidisciplinary HF team based on standard criteria. ${ }^{1,6,17}$ Briefly, patients were subjected to formal cardiopulmonary testing to determine functional capacity. $\mathrm{A} \mathrm{VO}_{2} \max$ of $14 \mathrm{~mL} / \mathrm{min} / \mathrm{m}^{2}$ was used as a cutoff to determine the need for advanced therapies. HTx eligibility was assessed by additional screening for peripheral vascular disease, pulmonary hypertension, and other comorbidities. Among the 133 patients in the HRS group, 65 patients $(49 \%)$ were deemed to be HTx-ineligible, and $68(51 \%)$ were HTx-eligible (Figure 1).

\section{Patient Selection for HRS}

Patient selection for HRS was made on a case-by-case basis during our multidisciplinary HF team conference in consideration of the risk, patient's body habitus, and the potential of myocardial recovery. In patients with ischemic cardiomyopathy, myocardial viability was assessed by late gadolinium-enhanced magnetic resonance imaging or single-photonemission computed tomography to determine the potential of recovery. We considered revascularization if patients had at least 1 good coronary target with a tight proximal lesion. Nonviable myocardium in a left anterior descending artery distribution was not necessarily an exclusion criterion if there was viable myocardium in other coronary distributions and/or LV reconstruction was possible. In valve surgery patients, our accrued experience during this time frame led us to avoid mitral valve (MV) surgery in patients with an LV end-diastolic diameter (LVDd) $>65 \mathrm{~mm} .{ }^{18}$ Dobutamine stress echocardiography was performed for aortic valve (AV) surgery patients to determine their functional reserve and to stratify their risk. Patients who had a history of myocardial infarction and akinetic or dyskinetic LV aneurysms were considered for LV reconstruction as previously described. ${ }^{19,20}$

\section{Data Collection}

All perioperative and demographic data were routinely abstracted from the patient chart and collected prospectively in our institution's surgical database. Follow-up data were obtained from the surgeon's office chart, our electronic medical record, or by contact with the patient's referring cardiologist. Clinical follow-up was $100 \%$ complete.

\section{Statistical Analysis}

In-hospital mortality was defined as any death occurring during the index hospital admission or within 30 days of surgery. ${ }^{21}$ All data are described as means with standard deviations, median with 25 th and 75 th percentiles, and frequencies, as appropriate. A prespecified subgroup 


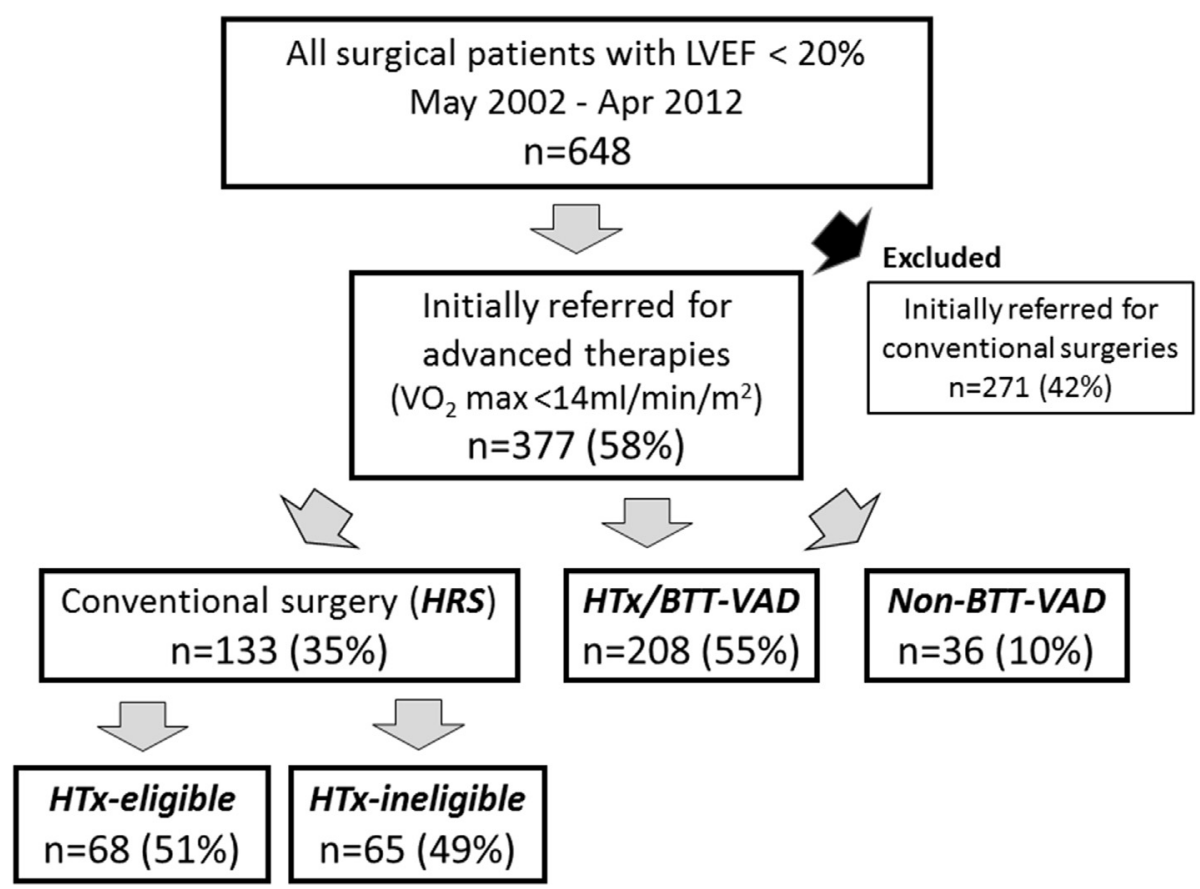

FIGURE 1. Description of patient enrollment. $L V E F$, Left ventricular ejection fraction; $V_{2}$ max, maximal oxygen consumption; $H R S$, high-risk conventional surgery; $H T x$, heart transplantation; $B T T$, bridge-to-transplant; $V A D$, ventricular assist device.

analysis was performed comparing patients who were HTx-eligible with those who were not by using Fisher exact test, Student $t$ test assuming unequal variance between study groups (Satterthwaite method), and Cox regression models, as appropriate.

A propensity score was generated to determine the probability of patients to undergo high-risk surgery instead of advanced support. First, patients eligible for HTx who underwent high-risk operations were compared with patients who underwent HTx or BTT-VAD and then, patients who underwent high-risk operations but were not eligible for HTx were compared with patients who underwent non-BTT-LVAD implantation. The propensity score in both cases was based on 8 variables selected for their clinical relevance: age, gender, New York Heart Association (NYHA) classification, hypertension, creatinine, diabetes, atrial fibrillation, and hypercholesterolemia. Both propensity scores achieved a high degree of segregation (c-statistics $>0.85$ in both cases), hence direct matching was not possible. Survival between patients undergoing high-risk operations and their respective controls based on patient eligibility was compared by using Cox regression models using both unadjusted and propensityadjusted models. As we aimed to compare the surgical outcomes of each approach instead of overall outcomes, we defined time zero as the date of first surgery, not the date of decision. Patient survival stratified by HTx eligibility is reported along with the contemporary data of adult HTx and DTLVAD from the International Society for Heart and Lung Transplantation (ISHLT) and Interagency Registry for Mechanically Assisted Circulatory Support (INTERMACS) for qualitative comparison. ${ }^{22-26}$

All statistical analyses were performed using SAS v9.3 (SAS Institute, Inc, Cary, NC). The study was approved by the local ethics committee of our institution, and written informed consent was waived because of the retrospective nature of this study.

\section{RESULTS}

\section{Patient Characteristics of HRS}

Patient demographics and surgical characteristics of our HRS group are presented in Table 1 . The mean age was
$63 \pm 10$ years and $83 \%$ were men. All patients had LVEF $<20 \%$ and $\mathrm{VO}_{2} \max <14 \mathrm{~mL} / \mathrm{min} / \mathrm{m}^{2}$, and $79 \%$ of patients were NYHA class III/IV. The etiology of HF was ischemic in $121(91 \%)$, valvular in $4(3 \%)$, and $8(6 \%)$ patients presented with idiopathic dilated cardiomyopathy (DCM). The primary lesions for surgical interventions in valvular patients were aortic stenosis $(\mathrm{n}=3)$ and aortic regurgitation $(\mathrm{n}=1)$. Patients felt to have DCM were also found to have low-flow, low-gradient aortic stenosis $(n=5)$ or aortic regurgitation $(\mathrm{n}=1)$, and $2(25 \%)$ patients underwent repair for functional mitral regurgitation. The perioperative risk calculated by EuroSCORE II scoring system in our population was $11.3 \% \pm 10.8 \%$.

As expected, HTx-ineligible patients were older than HTx-eligible patients ( $70 \pm 8$ vs $57 \pm 8$ years, $P<.001)$. HTx-ineligible patients had more comorbidities including peripheral vascular disease $(29 \%$ vs $12 \%, P=.02)$, higher serum creatinine levels $(111 \pm 57$ vs $96 \pm 24 \mu \mathrm{mol} / \mathrm{L}$, $P=.04)$, and chronic obstructive pulmonary disease (11\% vs $3 \%, P=.09$ ). Most HF etiology was ischemic in both groups (90\% vs $92 \%, P=.76)$. The EuroSCORE II perioperative risk was significantly higher in $\mathrm{HTx}$ ineligible patients compared with HTx-eligible patients $(13.9 \pm 13.0$ vs $8.9 \pm 7.4, P=.007)$.

\section{Short- and Midterm Outcomes of HRS}

Table 2 displays overall short- and midterm outcomes of our HRS group. In total, the in-hospital mortality was $12 \%$ $(\mathrm{n}=16)$. Ten cases $(63 \%)$ were due to low-output 
TABLE 1. Patient and surgical characteristics of high-risk conventional surgery

\begin{tabular}{|c|c|c|c|c|}
\hline Variables & All $(\mathbf{n}=133)$ & HTx-eligible $(n=68)$ & HTx-ineligible $(\mathrm{n}=65)$ & $\boldsymbol{P}$ \\
\hline \multicolumn{5}{|l|}{ Patient characteristics } \\
\hline Age, $y$, mean $\pm S D$ & $63 \pm 10$ & $57 \pm 8$ & $70 \pm 8$ & $<.001$ \\
\hline Sex, male & $110(83)$ & $57(84)$ & $53(82)$ & .82 \\
\hline NYHA class & & & & .08 \\
\hline III & $52(39)$ & $26(38)$ & $26(41)$ & \\
\hline IV & $52(39)$ & $32(47)$ & $20(31)$ & \\
\hline Left ventricular grade $4(\mathrm{LVEF}<20 \%)$ & $133(100)$ & $68(100)$ & $65(100)$ & n.a. \\
\hline Heart transplantation eligibility (Yes) & $68(51)$ & $68(100)$ & $0(0)$ & n.a. \\
\hline Etiology of heart failure & & & & .01 \\
\hline Ischemic & $121(91)$ & $61(90)$ & $60(92)$ & \\
\hline Valvular & $4(3)$ & $0(0.0)$ & $4(6)$ & \\
\hline Aortic stenosis & $3(75)$ & $0(0.0)$ & $3(75)$ & \\
\hline Aortic regurgitation & $1(25)$ & $0(0.0)$ & $1(25)$ & \\
\hline Dilated cardiomyopathy & $8(6)$ & $7(10)$ & $1(2)$ & \\
\hline Aortic stenosis & $5(63)$ & $4(57)$ & $1(100)$ & \\
\hline Aortic regurgitation & $1(13)$ & $1(14)$ & $0(0)$ & \\
\hline Functional mitral regurgitation & $2(25)$ & $2(29)$ & $0(0)$ & \\
\hline Atrial fibrillation or flutter & $15(11)$ & $6(9)$ & $9(14)$ & .42 \\
\hline Diabetes mellitus & $65(49)$ & $35(52)$ & $30(46)$ & .60 \\
\hline Medically treated hypertension & $77(58)$ & $35(52)$ & $42(65)$ & .16 \\
\hline Diet or medically treated hyperlipidemia & $103(77)$ & $52(77)$ & $51(79)$ & .84 \\
\hline Family history heart disease & $58(44)$ & $31(46)$ & $27(42)$ & .73 \\
\hline Smoking history & $97(73)$ & $47(69)$ & $50(77)$ & .34 \\
\hline Dialysis & $1(0.8)$ & $0(0)$ & $1(2)$ & .49 \\
\hline Chronic obstructive pulmonary syndrome & $9(7)$ & $2(3)$ & $7(11)$ & .09 \\
\hline Previous stroke or trans-ischemic attack & $16(12)$ & $7(10)$ & $9(14)$ & .60 \\
\hline Peripheral vascular disease & $27(20)$ & $8(12)$ & $19(29)$ & .02 \\
\hline Carotid stenosis $>70 \%$ (unilateral + bilateral $)$ & $8(6)$ & $2(3)$ & $6(9)$ & .16 \\
\hline Serum creatinine level, $\mu \mathrm{mol} / \mathrm{L}$ & $103 \pm 45$ & $96 \pm 24$ & $111 \pm 57$ & .04 \\
\hline Previous cardiac surgery & $5(4)$ & $3(4)$ & $2(3)$ & 1.00 \\
\hline Myocardial infarction within $30 \mathrm{~d}$ & $26(20)$ & $11(16)$ & $15(23)$ & .38 \\
\hline EuroSCORE II & $11.3 \pm 10.8$ & $8.9 \pm 7.4$ & $13.9 \pm 13.0$ & .007 \\
\hline \multicolumn{5}{|l|}{ Surgical characteristics } \\
\hline Urgent/Emergent surgery & $5(4)$ & $2(3)$ & $3(5)$ & .48 \\
\hline CABG & $122(92)$ & $62(91)$ & $60(93)$ & 1.00 \\
\hline Total number of distal grafts & & & & .25 \\
\hline 1 & $10(8)$ & $4(6)$ & $6(10)$ & \\
\hline 2 & $14(11)$ & $5(8)$ & $9(15)$ & \\
\hline 3 & $35(29)$ & $17(27)$ & $18(30)$ & \\
\hline $4+$ & $63(52)$ & $36(58)$ & $27(45)$ & \\
\hline Aortic valve surgery & $16(12)$ & $6(9)$ & $10(15)$ & .29 \\
\hline Mitral valve surgery & $42(32)$ & $27(40)$ & $15(23)$ & .002 \\
\hline Repair & $37(88)$ & $25(93)$ & $12(80)$ & \\
\hline Replacement & $5(11)$ & $2(7)$ & $3(20)$ & \\
\hline Tricuspid valve surgery & $6(5)$ & $5(7)$ & $1(2)$ & .21 \\
\hline Left ventricular reconstruction & $51(38)$ & $29(43)$ & $22(34)$ & .37 \\
\hline Cardiopulmonary bypass time, min & $113 \pm 33$ & $113 \pm 32$ & $112 \pm 34$ & .76 \\
\hline Cross-clamp time, $\min$ & $82 \pm 31$ & $87 \pm 25$ & $77 \pm 35$ & .06 \\
\hline
\end{tabular}

Values are $\mathrm{n}(\%)$ unless otherwise indicated. $H T x$, Heart transplantation; $S D$, standard deviation; NYHA, New York Heart Association; $L V E F$, left ventricular ejection fraction; n.a., not applicable because the groups were either identical or completely disparate; $C A B G$, coronary artery bypass grafting.

syndrome (LOS). Among the 16 deaths, 15 were ischemic and 1 dilated cardiomyopathy patients. Among the patients with ischemic etiology, the in-hospital mortality with corresponding EuroSCORE II of isolated CABG $(\mathrm{n}=43)$, $\mathrm{CABG}+\mathrm{LV}$ reconstruction $(\mathrm{n}=34), \mathrm{CABG}+\mathrm{MV} \pm$ tricuspid valve $(\mathrm{n}=21)$, CABG $+\mathrm{LV}$ reconstruction + MV $(\mathrm{n}=15)$ was $2.3 \%(8.0 \% \pm 7.1 \%), 11.8 \%$ $(12.2 \% \pm 13.7 \%), 14.3 \%(11.2 \% \pm 7.0 \%)$, and $20.0 \%$ $(18.7 \% \pm 10.3 \%)$, respectively. The in-hospital mortality of isolated CABG was significantly lower than that of any 
TABLE 2. Short- and midterm outcomes of high-risk conventional surgery

\begin{tabular}{|c|c|c|c|c|}
\hline Variables & All $(n=133)$ & HTx-eligible $(n=68)$ & HTx-ineligible $(n=65)$ & $\boldsymbol{P}$ \\
\hline \multicolumn{5}{|l|}{ Short-term outcomes } \\
\hline Ventilation time, $\mathrm{h}$ (range) & $9(6-19)$ & $8(5-19)$ & $11(6-24)$ & .34 \\
\hline ICU stay, h (range) & $74(41-138)$ & $69(26-130)$ & $74(23-142)$ & .86 \\
\hline Hospital stay, d (range) & $9(7-13)$ & $8(6-12)$ & $9(6-13)$ & .83 \\
\hline Insertion of IABP & $22(17 \%)$ & $11(16 \%)$ & $11(17 \%)$ & 1.00 \\
\hline Reoperation for bleeding & $9(7 \%)$ & $4(6 \%)$ & $5(8 \%)$ & .74 \\
\hline High-dose dopamine use & $68(51 \%)$ & $32(47 \%)$ & $36(55 \%)$ & .39 \\
\hline Low-output syndrome & $23(17 \%)$ & $10(15 \%)$ & $13(20 \%)$ & .49 \\
\hline Renal failure (dialysis required) & $5(4 \%)$ & $3(4 \%)$ & $2(3 \%)$ & 1.00 \\
\hline Pulmonary complications & $31(23 \%)$ & $15(22 \%)$ & $16(25 \%)$ & .84 \\
\hline Persistent neurological deficit & $3(2 \%)$ & $0(0 \%)$ & $3(5 \%)$ & .20 \\
\hline Sternal infection & $3(2 \%)$ & $2(3 \%)$ & $1(2 \%)$ & 1.00 \\
\hline Mortality & $16(12 \%)$ & $6(9 \%)$ & $10(15 \%)$ & .29 \\
\hline LOS & $10(63 \%)$ & $4(67 \%)$ & $6(60 \%)$ & \\
\hline MOF & $2(13 \%)$ & $0(0 \%)$ & $2(20 \%)$ & \\
\hline Arrhythmia & $1(6 \%)$ & $0(0 \%)$ & $1(10 \%)$ & \\
\hline Sepsis & $1(6 \%)$ & $1(17 \%)$ & $0(0 \%)$ & \\
\hline Pneumonia & $1(6 \%)$ & $1(17 \%)$ & $0(0 \%)$ & \\
\hline Unknown & $1(6 \%)$ & $0(0 \%)$ & $1(10 \%)$ & \\
\hline \multicolumn{5}{|l|}{ Midterm outcomes } \\
\hline Duration of follow-up, y (range) & $4.9(2.3-7.1)$ & $4.7(2.3-7.2)$ & $3.7(0.9-6.7)$ & .10 \\
\hline Mortality & $46(35 \%)$ & $16(24 \%)$ & $30(46 \%)$ & .01 \\
\hline Cardiac cause & $20(44 \%)$ & $9(56 \%)$ & $11(37 \%)$ & \\
\hline Noncardiac cause & $12(26 \%)$ & $4(25 \%)$ & $8(27 \%)$ & \\
\hline Unknown & $14(30 \%)$ & $3(19 \%)$ & $11(37 \%)$ & \\
\hline NYHA class at last follow-up & & & & .82 \\
\hline I & $28(29 \%)$ & $16(30 \%)$ & $12(29 \%)$ & \\
\hline II & $39(41 \%)$ & $21(39 \%)$ & $18(43 \%)$ & \\
\hline III & $28(29 \%)$ & $17(32 \%)$ & $11(26 \%)$ & \\
\hline IV & $1(1 \%)$ & $0(0 \%)$ & $1(2 \%)$ & \\
\hline Hospitalization for heart failure & $22(19 \%)$ & $13(21 \%)$ & $9(16 \%)$ & .64 \\
\hline
\end{tabular}

Values are n (\%) unless otherwise indicated. $H T x$, Heart transplantation; $I C U$, intensive care unit; $I A B P$, intra-aortic balloon pumping; $L O S$, low-output syndrome; $M O F$, multiple organ failure; NYHA, New York Heart Association.

combined procedures $(2.3 \%$ vs $14.3 \%, P=.03)$. The median (interquartile range) durations of intensive care unit and hospital stay were 74 (41-138) hours and $9^{7-13}$ days, respectively. Intra-aortic balloon pump (IABP) support was required in $17 \%(\mathrm{n}=22)$ postoperatively. After a median follow-up of 4.9 years (range 0 days to 11 years), 46 patients $(35 \%)$ were deceased. Survival at 5 and 10 years was $72 \% \pm 4 \%$ and $39 \% \pm 8 \%$. Notably, NHYA class at last follow-up was significantly improved from preoperative grade. In the comparison between the 2 subsets in our HRS group, there was no significant difference in the incidence of postoperative complications. Midterm mortality was significantly higher in HTx-ineligible patients (HR 2.37 [95\% confidence interval (CI), 1.29-4.38], $P=.006)$. NYHA class was considerably improved from preoperative grade in both subsets.

Figures 2 and 3 illustrate the comparison of the survival curves between our HRS and advanced therapy groups. The patient demographics used for the adjustment in all groups are displayed in Table 3 . The contemporary data of adult HTx and DT-LVAD from ISHLT and INTERMACS was also superimposed for comparison. ${ }^{22,23}$ As shown in Figure 2, our HTx-eligible HRS patients had comparable long-term survival to our HTx/BTT-VAD patients (unadjusted HR 0.97 [95\% CI, 0.55-1.69], $P=.91$; propensityadjusted HR 1.48 [95\% CI, 0.66-3.29], $P=.34$ ). Similarly in Figure 3, the survival of our HTx-ineligible HRS patients was comparable to the survival after our non-BTT-LVAD therapy (unadjusted HR $0.57 \quad[95 \% \mathrm{CI}, 0.32-1.02]$, $P=.06$; propensity-adjusted HR 0.49 [95\% CI, 0.16 $1.50], P=.21)$.

\section{Independent Risk Factors for Survival Outcome of HRS}

The multivariable analysis of variables associated with long-term mortality is presented in Table 4 . In addition to HTx ineligibility, nonischemic HF etiology was identified as an independent risk factor. Nonelective surgery, higher preoperative creatinine, and longer cardiopulmonary bypass time also correlated with long-term mortality. 


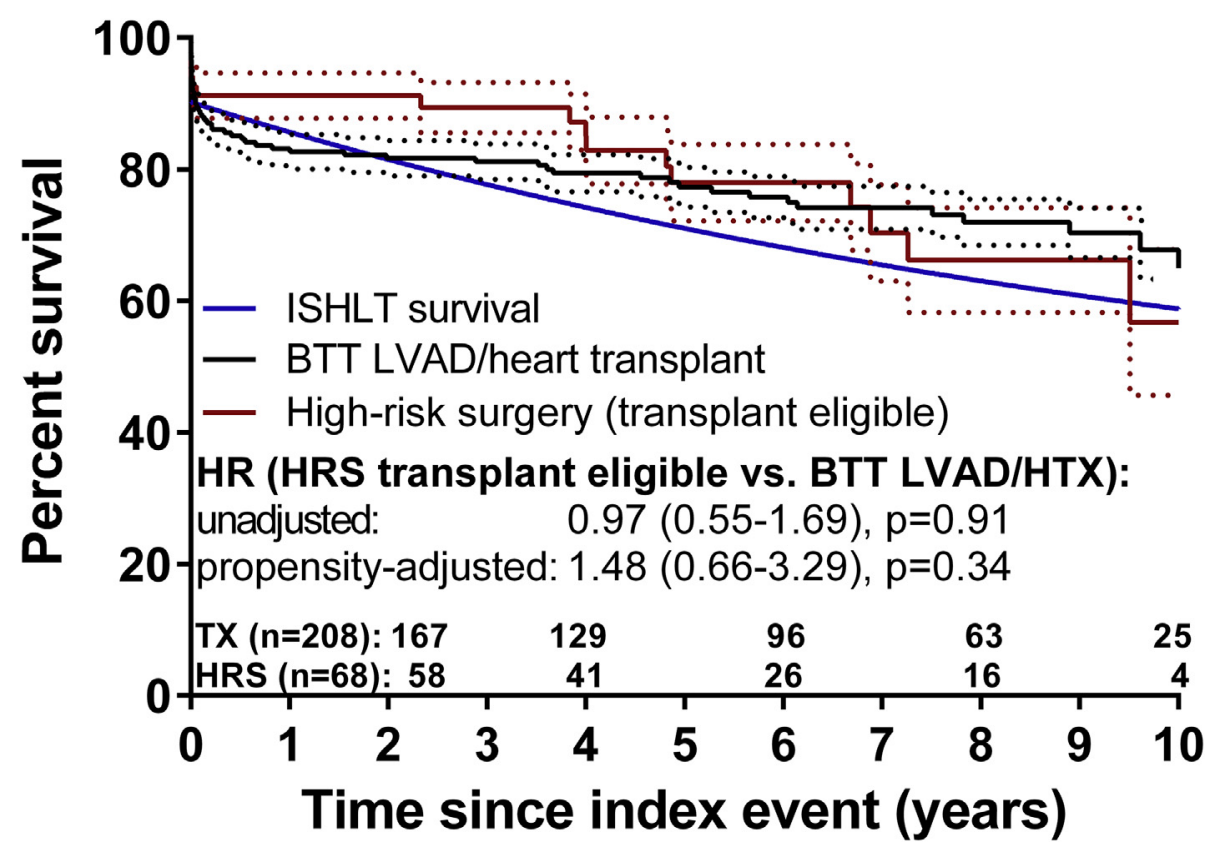

FIGURE 2. Comparison of the survival curves between our high-risk conventional surgery (HRS) for transplant-eligible patients and heart transplantation $(H T x)$ or bridge-to-transplant left ventricular assist device $(B T T-L V A D)$ patients, benchmarked to contemporary adult HTx data from International Society for Heart and Lung Transplantation (ISHLT). ${ }^{22}$ The index event was defined as the time of first surgery. HR, Hazard ratio.

\section{DISCUSSION}

\section{Patient Population}

This study investigated the outcomes of conventional cardiac surgery in patients with end-stage HF who would otherwise have been listed for HTx or offered LVAD support. Although there are many studies reporting the outcomes of cardiac surgery in patients with low LVEF, $^{7-15,20,27-29}$ the current study represents an extreme subset that met functional criteria for advanced surgical therapies $\left(\mathrm{VO}_{2} \max <14 \mathrm{~mL} / \mathrm{min} / \mathrm{m}^{2}\right)$. Although many patients with LVEF $<20 \%$ did indeed proceed to heart transplant and/or LVAD, 404 patients underwent

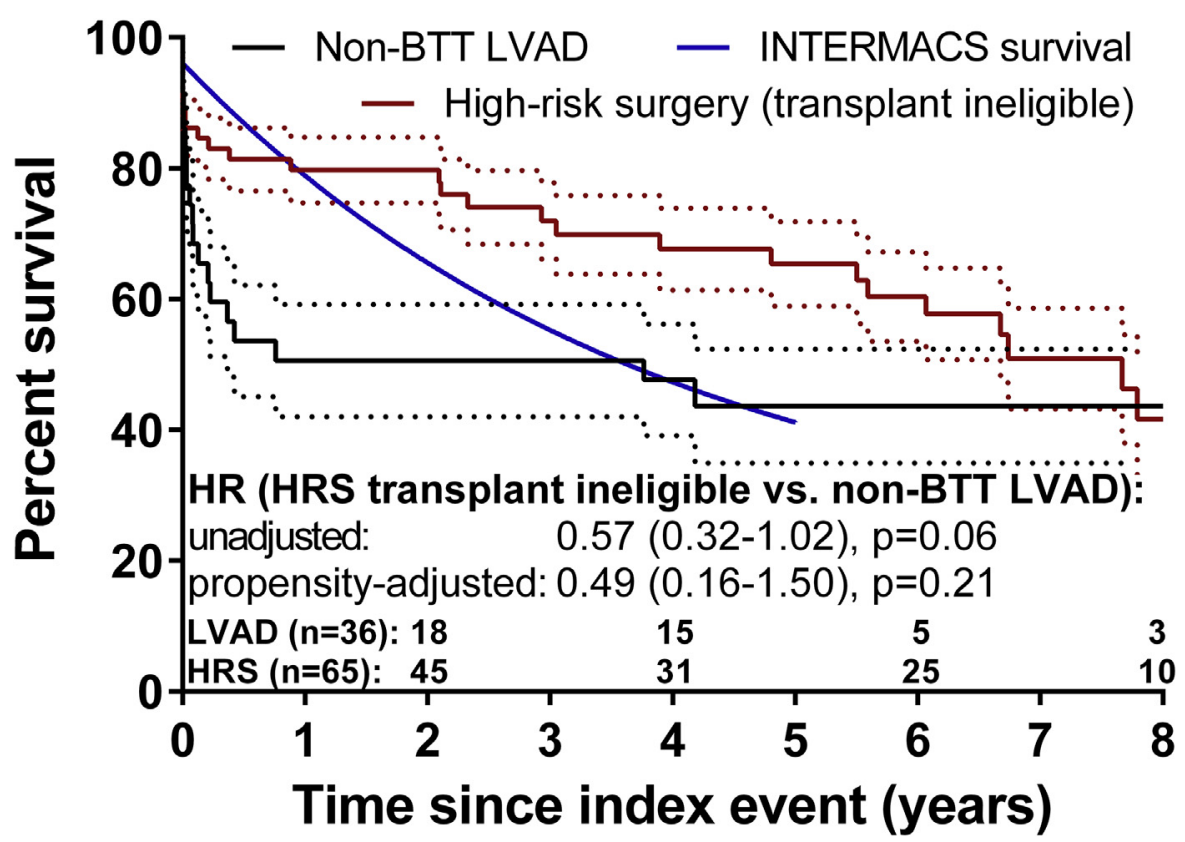

FIGURE 3. Comparison of the survival curves between our high-risk conventional surgery (HRS) for transplant-ineligible patients and non-bridge-to-transplant left ventricular assist device (non-BTT-LVAD), benchmarked to contemporary LVAD destination therapy data from Interagency Registry for Mechanically Assisted Circulatory Support (INTERMACS). ${ }^{23}$ The index event was defined as the time of first surgery. HR, Hazard ratio. 
TABLE 3. Patient demographics of high-risk conventional surgery and advanced surgical therapies used for propensity score adjustment

\begin{tabular}{lcccc}
\hline \multicolumn{1}{c}{ Variables } & HTx-eligible $(\mathbf{n}=\mathbf{6 8})$ & BTT-LVAD/HTx $(\mathbf{n}=\mathbf{2 0 8})$ & HTx-ineligible $(\mathbf{n}=\mathbf{6 5})$ & Non-BTT-LVAD $(\mathbf{n}=\mathbf{3 6})$ \\
\hline Age, y, mean \pm SD & $57 \pm 8$ & $48 \pm 12$ & $70 \pm 8$ & $49 \pm 14$ \\
Sex, male & $57(84)$ & $139(67)$ & $53(82)$ & $27(75)$ \\
NYHA class & & & & \\
$\quad$ III & $26(38)$ & $53(27)$ & $26(39)$ & $5(14)$ \\
IV & $32(48)$ & $126(65)$ & $20(31)$ & $22(63)$ \\
Hypertension & $35(51)$ & $29(14)$ & $42(65)$ & $5(14)$ \\
Creatinine, umol/L, mean \pm SD & $96 \pm 24$ & $122 \pm 92$ & $111 \pm 57$ & $142 \pm 61$ \\
Diabetes & $35(51)$ & $35(17)$ & $30(46)$ & $10(28)$ \\
Atrial fibrillation & $15(22)$ & $27(13)$ & $29(45)$ & $12(34)$ \\
Hypercholesterolemia & $51(78)$ & $60(29)$ & $51(78)$ & $12(33)$ \\
\hline
\end{tabular}

Values are $\mathrm{n}(\%)$ unless otherwise indicated. $H T x$, Heart transplantation; $B T T$, bridge-to-transplant; $L V A D$, left ventricular assist device; $S D$, standard deviation; $N Y H A$, New York Heart Association.

conventional surgery. Only $133(33 \%)$ of these patients met inclusion criteria for our study $\left(\mathrm{VO}_{2} \max <14\right)$, underscoring the fact that these patients are an extreme subset of patients with LV dysfunction.

According to the 2013 American College of Cardiology Foundation/American Heart Association Guidelines for the Management of Heart Failure, the general indications for referral for mechanical circulatory support include patients with LVEF $<25 \%$ and NYHA class III-IV (Class IIa, Evidence level B). ${ }^{1}$ In the present study, all patients had LVEF $<20 \%$ and the percentage of NYHA class III/ IV was $79 \%$. Maltais et al $^{13}$ reported their acceptable outcomes of a combined CABG and MV surgery in patients with severe ischemic cardiomyopathy compared with their DT-LVAD results. In their study, they used LVEF $<25 \%$ as an inclusion criterion for the conventional surgery group to match up with their DT-LVAD population; however, other parameters indicating HF grade or functional capacity were not reported. Kainuma et $\mathrm{al}^{28}$ reported their outcomes of MV repair for functional MV regurgitation in patients with advanced HF. In their study, all patients had stage C/ D HF symptoms and $91 \%$ were in NYHA class III/IV; nevertheless, their LVEF cutoff value was $40 \%$. Thus, we believe that our study has investigated the outcomes of conventional surgery in an advanced HF population compared with other published studies. Importantly, in addition to poor $\mathrm{EF}(<20 \%)$, we included an objective criterion $\left(\mathrm{VO}_{2}\right.$ $\max <14 \mathrm{~mL} / \mathrm{min} / \mathrm{m}^{2}$ ) and the subjective referral of these patients to our HF team for consideration of advanced therapies.

In the present study, an ischemic etiology was evident in more than $90 \%$ of the patients. According to a large observational study of HF in a general population in the United Kingdom, coronary artery disease is the cause of $52 \%$ of $\mathrm{HF}$ in patients younger than 75 , followed by $13 \%$ idiopathic and $10 \%$ valvular diseases. ${ }^{30}$ This discrepancy in the proportion of HF etiology between our surgical patients and the general population in the United Kingdom likely reflects our bias to offer surgery to patients with ischemic heart disease.
Despite an overwhelming ischemic population, a large proportion underwent MV surgery (32\%). Not surprisingly, LV reconstruction was also performed in $38 \%$ of this cohort. A previous report from our group has identified that the combination of LV repair and MV intervention is associated with high mortality and morbidity. ${ }^{18}$ This prior study did not restrict inclusion to patients meeting criteria for advanced therapy and, as such, it is not surprising that the overall mortality in our current study is relatively high at $12 \%$. Fedoruk et $\mathrm{al}^{27}$ described that they performed $25 \%$ concomitant MV surgery and $17 \%$ LV remodeling surgery in their patients with ischemic cardiomyopathy with LVEF $<35 \%$ with an overall mortality of $8 \%$. These numbers suggest that our patients were more advanced in terms of HF stage as well as LV remodeling.

\section{Outcomes of HRS for Patients With End-Stage HF}

Our 5-year survival $(72 \% \pm 4 \%)$ was comparable with previous studies. ${ }^{7,9,11,13-15,28}$ Kunadian et $\mathrm{al}^{7}$ conducted a meta-analysis of 26 nonrandomized studies with 4119 cases involving isolated CABG for patients with LVEF $<35 \%$ and the overall 5 -year survival was $73 \%$. Again, these studies included a wide range of patients with " $\mathrm{LV}$ dysfunction" and no study isolated their analyses to an advanced therapy-eligible population. Ahmed et $\mathrm{al}^{11}$ studied the outcomes of isolated CABG in 162 patients with LVEF $<30 \%$ and their 5 -year survival was $69 \%$. Kainuma et $\mathrm{al}^{28}$ reported their results with MV surgery $\pm \mathrm{CABG} \pm$ surgical ventricular reconstruction for 208 patients with advanced cardiomyopathy with LVEF $<40 \%$ and end-systolic volume $>60 \mathrm{~mL} / \mathrm{m}^{2}$. Their 5 -year survival stratified by renal function was $77 \%, 45 \%$, and $70 \%$ in normal, severely impaired, and hemodialysis patients, respectively. Halkos et $\mathrm{al}^{14}$ also described their outcomes for $773 \mathrm{AV}$ replacements for aortic stenosis $\pm \mathrm{CABG}$ and the 5-year survival rate in patients with $\mathrm{LVEF}<40 \%$ was $62 \%$.

The STICH trial was designed to determine the benefit of CABG in patients with $\mathrm{LV}$ dysfunction due to ischemic cardiomyopathy. ${ }^{29}$ Although the primary outcome analysis failed to show a superiority of CABG compared with 
TABLE 4. Independent risk factors for long-term mortality of highrisk conventional surgery

\begin{tabular}{lcc}
\hline \multicolumn{1}{c}{ Risk factor } & HR $(\mathbf{9 5} \% \mathbf{C I})$ & $\boldsymbol{P}$ \\
\hline Transplant-eligible & $0.40(0.20-0.80)$ & .01 \\
Nonischemic etiology of heart failure & $2.82(1.00-7.94)$ & .05 \\
Nonelective surgery & $2.10(1.13-3.88)$ & .02 \\
Preoperative creatinine & & \\
$\quad>150 \mu \mathrm{mol} / \mathrm{L}$ & $3.82(1.55-9.39)$ & .003 \\
$\quad 100-149 \mu \mathrm{mol} / \mathrm{L}$ & $1.98(1.00-3.92)$ & .05 \\
$\quad<100 \mu \mathrm{mol} / \mathrm{L}$ & Reference & \\
Longer cardiopulmonary bypass time & $1.49(1.11-2.00)$ & .05 \\
$\quad$ per 30 min) & & \\
\hline$H R$, Hazard ratio; $C I$, confidence interval. & &
\end{tabular}

medical therapy alone, it is difficult to compare the findings with our study because the profiles of our patients were much sicker than the ones in STICH. For example, the LVEF cutoff in the STICH trial was 35\% and most of them had NYHA class II or III symptoms (class II $50 \%$, III $35 \%$ ). In addition, most investigators believe that the high crossover rate from medical therapy to surgery in the first year after randomization significantly confounded the interpretation of the STICH study. Indeed, a post hoc analysis examining "as-treated" patients revealed a significant benefit to surgical intervention with respect to overall mortality and freedom from repeat hospitalization. Our results suggest that even in a higher risk surgical population, the benefits of surgical revascularization lead to higher than expected survival.

As we expected, our in-hospital mortality $(12 \%)$ seemed to be relatively high given that the mortality in the previous studies ranged between $5 \%$ and $11 \% .^{7,9,11,13-15,27,28}$ The incidence of other postoperative complications was similar (16\%-20\% need for IABP, $4 \%-6 \%$ reoperation for bleeding, 4\%-5\% neurological deficit). We believe that this modestly higher early mortality reflects the advanced disease state in our population and the complexity of the surgery. Indeed, the calculated perioperative risk using the EuroSCORE II scoring system in our population was $11.3 \% \pm 10.8 \%$, and that was very close to our observed early mortality. In addition, the early mortality in our isolated patients with CABG was significantly lower than the one in the patients who underwent any combined procedures $(2.3 \%$ vs $14.3 \%, P=.03)$. Interestingly, the mortality was much lower than their estimated risk by EuroSCORE $(8.0 \% \pm 7.1 \%)$. More importantly, our longterm results indicate that once these patients are through the high-risk perioperative course, they continue on with reasonably acceptable survival.

Because our HRS and advanced surgical therapy groups had different patient demographics, we used propensity adjustment to compare the survival outcome instead of matching, as described in Method section. Of note, the results of comparisons in propensity-matched small subsets were essentially similar to those of the propensity-adjusted model (data not shown). Both in unadjusted and adjusted models, the survival after our HRS in HTx-eligible patients was comparable to our HTx/BTT-VAD survival. In addition, the HTx-ineligible subset in our HRS group had comparable survival to our non-BTT-LVAD patients. These results suggest that HRS may be an alternative option to the advanced surgical therapies for highly selected patients with end-stage HF.

\section{Patient Selection for HRS}

In addition to conventional risk (eg, frailty, comorbidities) and potential of myocardial recovery (eg, myocardial viability and functional reserve), the etiology of HF may also need to be considered before offering conventional surgeries for patients with end-stage HF. Our results identified that patients with ischemic HF had more favorable midterm survival than other cardiomyopathies. On the other hand, it is known that the short- and long-term mortality after HTx in ischemic etiology recipients is higher than other groups. ${ }^{22}$ Patients with ischemic HF also have a higher mortality while waiting for HTx compared with nonischemic patients. ${ }^{31}$ Taken together, patients with ischemic HF may be more suitable candidates for high-risk cardiac surgery than nonischemic patients. Particularly isolated CABG may be safely performed even for patients who are considered high risk based on the current scoring system.

\section{Limitations}

This study was a retrospective cohort investigation with a small number of subjects; therefore, any conclusions are limited and are hypothesis generating. In the survival analyses, we used the date of first surgery as time zero instead of the date of decision, as we aimed to compare the surgical outcomes of each approach instead of overall outcomes. Thus, it is possible that we are underestimating the mortality of the VAD/transplant route because we did not include the waitlist mortality, which may augment the survival benefit of the conventional surgery strategy.

\section{CONCLUSIONS}

The outcomes of conventional cardiac surgery in highly selected patients with end-stage HF were acceptable and the long-term survival was comparable with the one after our advanced surgical therapies. Particularly for patients with an ischemic cardiomyopathy, strong consideration for conventional surgery should be given before offering advanced therapies such as transplantation or LVAD.

\section{Conflict of Interest Statement}

Dr McDonald reports personal fees from Novartis for work on their advisory board and clinical trials. Dr Rao reports personal fees for consulting work for St. Jude Medical. 
All other authors have nothing to disclose with regard to commercial support.

\section{References}

1. Yancy CW, Jessup M, Bozkurt B, Butler J, Casey DE, Drazner MH, et al. 2013 ACCF/AHA guideline for the management of heart failure: executive summary: a report of the American College of Cardiology Foundation/American Heart Association Task Force on practice guidelines. Circulation. 2013;128:1810-52.

2. Colvin-Adams M, Smithy JM, Heubner BM, Skeans MA, Edwards LB, Waller C, et al. OPTN/SRTR 2012 Annual Data Report: heart. Am J Transplant. 2014;14: 113-38.

3. Rose EA, Gelijns AC, Moskowitz AJ, Heitjan DF, Stevenson LW, Dembitsky W, et al. Long-term use of a left ventricular assist device for end-stage heart failure. N Engl J Med. 2001;345:1435-43.

4. Slaughter MS, Rogers JG, Milano CA, Russell SD, Conte JV, Feldman D, et al. Advanced heart failure treated with continuous-flow left ventricular assist device. N Engl J Med. 2009;361:2241-51.

5. Owens AT, Jessup M. Should left ventricular assist device be standard of care for patients with refractory heart failure who are not transplantation candidates? Left ventricular assist devices should not be standard of care for transplantationineligible patients. Circulation. 2012;126:3088-94.

6. Allen LA, Stevenson LW, Grady KL, Goldstein NE, Matlock DD, Arnold RM, et al. Decision making in advanced heart failure: a scientific statement from the American Heart Association. Circulation. 2012;125:1928-52.

7. Kunadian V, Zaman A, Qiu W. Revascularization among patients with severe left ventricular dysfunction: a meta-analysis of observational studies. Eur J Heart Fail. 2011;13:773-84.

8. Bishay ES, Mccarthy PM, Cosgrove DM, Hoercher KJ, Smedira NG, Mukherjee D, et al. Mitral valve surgery in patients with severe left ventricular dysfunction q. Eur J Cardiothorac Surg. 2000;17:213-21.

9. Czer LSC, Goland S, Soukiasian HJ, Gallagher S, De Robertis MA, Mirocha J, et al. Aortic valve replacement or heart transplantation in patients with aortic stenosis and severe left ventricular dysfunction. Transplant Proc. 2013;45:364-8.

10. Bhudia SK, McCarthy PM, Kumpati GS, Helou J, Hoercher KJ, Rajeswaran J, et al. Improved outcomes after aortic valve surgery for chronic aortic regurgitation with severe left ventricular dysfunction. J Am Coll Cardiol. 2007;49: 1465-71.

11. Ahmed WA, Tully PJ, Baker RA, Knight JL. Survival after isolated coronary artery bypass grafting in patients with severe left ventricular dysfunction. Ann Thorac Surg. 2009;87:1106-12.

12. Tarantini G, Buja P, Scognamiglio R, Razzolini R, Gerosa G, Isabella G, et al. Aortic valve replacement in severe aortic stenosis with left ventricular dysfunction: determinants of cardiac mortality and ventricular function recovery. Eur J Cardiothoracic Surg. 2003;24:879-85.

13. Maltais S, Tchantchaleishvili V, Schaff HV, Daly RC, Suri RM, Dearani JA, et al. Management of severe ischemic cardiomyopathy: left ventricular assist device as destination therapy versus conventional bypass and mitral valve surgery. $J$ Thorac Cardiovasc Surg. 2014;147:1246-50.

14. Halkos ME, Chen EP, Sarin EL, Kilgo P, Thourani VH, Lattouf OM, et al. Aortic valve replacement for aortic stenosis in patients with left ventricular dysfunction. Ann Thorac Surg. 2009;88:746-51.

15. Appoo J, Norris C, Merali S, Graham MM, Koshal A, Knudtson ML, et al. Longterm outcome of isolated coronary artery bypass surgery in patients with severe left ventricular dysfunction. Circulation. 2004;110:II13-7.

16. Hunt SA, Abraham WT, Chin MH, Feldman AM, Francis GS, Ganiats TG, et al. 2009 focused update incorporated into the ACC/AHA 2005 Guidelines for the Diagnosis and Management of Heart Failure in Adults: a report of the American College of Cardiology Foundation/American Heart Association Task Force on Practice Guidelines: developed in collaboration with the International Society for Heart and Lung Transplantation. Circulation. 2009;119: e391-479.

17. Mehra MR, Kobashigawa J, Starling R, Russell S, Uber PA, Parameshwar J, et al. Listing criteria for heart transplantation: International Society for Heart and Lung Transplantation guidelines for the care of cardiac transplant candidates - 2006. J Heart Lung Transplant. 2006;25:1024-42.

18. Jeganathan R, Maganti M, Badiwala MV, Rao V. Concomitant mitral valve surgery in patients undergoing surgical ventricular reconstruction for ischaemic cardiomyopathy. Eur J Cardiothorac Surg. 2013;43:1000-5.

19. Jones RH, Velazquez EJ, Michler RE, Sopko G, Oh JK, O'Connor CM, et al. Coronary bypass surgery with or without surgical ventricular reconstruction. $N$ Engl J Med. 2009;360:1705-17.

20. Witkowski TG, ten Brinke EA, Delgado V, Ng ACT, Bertini M, Marsan NA, et al Surgical ventricular restoration for patients with ischemic heart failure: determinants of two-year survival. Ann Thorac Surg. 2011;91:491-8.

21. Society of Thoracic Surgeons. Adult cardiac surgery data collection-training manual v2.81. Available at: http://www.sts.org/sts-national-database/databasemanagers/adult-cardiac-surgery-database/data-collection. Accessed December $21,2016$.

22. Lund LH, Edwards LB, Kucheryavaya AY, Benden C, Christie JD, Dipchand AI, et al. The Registry of the International Society for Heart and Lung Transplantation: thirty-first official adult heart transplant report-2014; focus theme: retransplantation. J Heart Lung Transplant. 2014;33:996-1008.

23. Kirklin JK, Naftel DC, Pagani FD, Kormos RL, Stevenson LW, Blume ED, et al Sixth INTERMACS annual report: a 10,000-patient database. J Heart Lung Transplant. 2014;33:555-64.

24. Shahian DM, O'Brien SM, Filardo G, Ferraris VA, Haan CK, Rich JB, et al. The Society of Thoracic Surgeons 2008 cardiac surgery risk models: part 1-coronary artery bypass grafting surgery. Ann Thorac Surg. 2009;88:S2-22.

25. O'Brien SM, Shahian DM, Filardo G, Ferraris VA, Haan CK, Rich JB, et al. The Society of Thoracic Surgeons 2008 cardiac surgery risk models: part 2-isolated valve surgery. Ann Thorac Surg. 2009;88:S23-42.

26. Shahian DM, O'Brien SM, Filardo G, Ferraris VA, Haan CK, Rich JB, et al. The Society of Thoracic Surgeons 2008 cardiac surgery risk models: part 3-valve plus coronary artery bypass grafting surgery. Ann Thorac Surg. 2009;88:S43-62.

27. Fedoruk LM, Tribble CG, Kern JA, Peeler BB, Kron IL. Predicting operative mortality after surgery for ischemic cardiomyopathy. Ann Thorac Surg. 2007; 83:2029-35; discussion 2035.

28. Kainuma S, Taniguchi K, Daimon T, Sakaguchi T, Funatsu T, Miyagawa S, et al Mitral valve repair for medically refractory functional mitral regurgitation in patients with end-stage renal disease and advanced heart failure. Circulation. 2012; 126:S205-13.

29. Velazquez EJ, Lee KL, Deja MA, Jain A, Sopko G, Marchenko A, et al. Coronary-artery bypass surgery in patients with left ventricular dysfunction. $N$ Engl J Med. 2011;364:1607-16.

30. Fox KF, Cowie MR, Wood DA, Coats AJ, Gibbs JS, Underwood SR, et al. Coronary artery disease as the cause of incident heart failure in the population. Eur Heart J. 2001;22:228-36.

31. Stevenson LW, Tillisch JH, Hamilton M, Luu M, Chelimsky-Fallick C, Moriguchi J, et al. Importance of hemodynamic response to therapy in predicting survival with ejection fraction $\leq 20 \%$ secondary to ischemic or nonischemic dilated cardiomyopathy. Am J Cardiol. 1990;66:1348-54.

Key Words: high-risk surgery, heart failure, mechanical circulatory support 